\title{
WHEN LOVE COMES CALLING: MEASURING SEXUAL SELECTION ON SAGEBRUSH CRICKETS
}

\author{
GeOFFrey D. OWER $\uparrow$ REBECCA A. SMITH $\uparrow$ KYle J. CARON $\uparrow$ SCOTT K. SAKAluK \\ ILLINOIS STATE UNIVERSITY $\uparrow$ NORMAL
}

\begin{abstract}
$\uparrow \quad$ ABSTRACT
Male sagebrush crickets exhibit differential mating success based on their previous mating experience: virgin males have a higher probability of obtaining a mating than do non-virgin males. Measures of lifetime mating success in male sagebrush crickets have revealed that the median mating frequency is one, with many males failing to secure a mate at all and a small minority obtaining two to four mates. The purpose of this study was to investigate the acoustic and morphological characteristics that make male sagebrush crickets attractive to females. Male crickets were captured from Deadman's Bar in Grand Teton National Park and their songs were recorded on subsequent evenings. Five song characteristics were measured including pulse duration, interpulse duration, dominant frequency, train duration, and intertrain duration. Multivariate selection analysis revealed significant linear and nonlinear selection on male song, with each of the five measured song characters contributing to male attractiveness. There was significant directional selection favoring longer pulse durations and shorter interpulse durations, which could be an honest indicator of male quality because these song characters likely impose high energetic costs. Significant stabilizing selection favored males with $\sim 13.2 \mathrm{kHz}$ calls and intermediate intertrain durations, which may be imposed by the auditory sensitivity of females.
\end{abstract}

\section{$\downarrow \quad$ INTRODUCTION}

The sagebrush cricket, Cyphoderris strepitans Gwynne and Morris (Orthoptera: Haglidae), is one of only three extant species of hump-winged grigs in North America, relatively obscure ensiferans that are restricted to mountainous areas of western North America. C. strepitans occurs in high-elevation sagebrush meadows nestled within coniferous forests in Wyoming and Colorado (Morris and Gwynne 1978). In Grand Teton National Park where the majority of field studies of $C$. strepitans have been conducted, sexual activity commences in mid-May. Each night of the breeding season, males emerge from the ground cover to secure a calling perch in sagebrush or lodgepole pine, where they sing to attract sexually receptive females.

Once a calling male has attracted a female, the female mounts the male dorsally to initiate a $\sim 3-5$ min mating that ends with the transfer of a spermatophore to the female. During the time that females remain mounted on males, they feed on the males' fleshy hind wings and ingest hemolymph seeping from the wounds they inflict. Males exhibit differential mating success based on their previous mating experience: virgin males have a higher probability of obtaining a mating than do non-virgin males of securing an additional mating, a pattern known as the virgin-male mating advantage (Morris et al. 1989, Sakaluk and Ivy 1999). The decreased likelihood of non-virgin mating apparently arises from the loss of hemolymph and costly immune responses that occur as a result of wing wounding during copulation (Leman et al. 2009). 
Although much of our previous work has focused on establishing the proximate basis of the virgin-male mating advantage, it has overshadowed a more fundamental question: what factors influences the probability of a male obtaining a mating in the first place? Measures of lifetime mating success in male $C$. strepitans have revealed that the median mating frequency is one, with many males failing to secure a mate at all and a small minority obtaining two to four mates. Because calling is required for mate attraction, it seems likely that certain features of males' calls influence variation in male mating success. Indeed, previous studies of acoustic Orthoptera have shown that the acoustical properties of a male's song can influence his attractiveness to females. What properties of a male's song might be relevant to female mate choice in $C$. strepitans? Previous studies of other cricket species have revealed that a male's song may reliably reflect his body size, age, degree of symmetry, nutritional condition, immunocompetence, degree of inbreeding and other correlates of male quality. Assuming these traits are heritable, females selecting particular males may secure indirect genetic benefits for their offspring or, in the case of gift-giving species such as C. strepitans, may secure greater direct material benefits by differentially responding to specific males.

The objectives of our research are to: 1) measure sexual selection in sagebrush crickets and 2) identify the morphological and acoustical traits that are the targets of sexual selection. Specifically, we recorded the song of males, and preserved them for subsequent morphological measurements. The study was conducted at the mid-point of the breeding season, and thus allowed collection of a roughly equal number of virgin and non-virgin males. If, as we hypothesize, sexual selection is acting on acoustical properties of males' songs and associated morphological structures, we predict that virgin and non-virgin males will differ systematically in at least some of these key traits.

\section{$\downarrow$ METHODS}

Male sagebrush crickets were collected from Deadman's Bar in Grand Teton National Park, Wyoming. The population was censused on a binightly basis to determine when it had reached an approximately 50:50 mated-to-unmated males ratio, which ensured that females had been given ample opportunity to choose the most attractive mates. Upon reaching this ratio, approximately 200 males were captured.
Captured males were transported to the University of Wyoming-National Park Service (UWNPS) Research Station where they were assigned a unique identification number, weighed, and their hindwings were inspected to ascertain their mating status. Males were placed individually into wire mesh cages and provisioned with sliced apple and sagebrush galls. On subsequent evenings, each male was recorded for 2 minutes using a Shure BG Microphone (Shure, Inc., Niles, IL) with the bioacoustics software Raven Pro (Cornell Lab of Ornithology, Ithaca, NY). Songs were digitized as 48 $\mathrm{kHz}, 16$-bit wav files. Because temperature could not be controlled and has a well documented effect on sagebrush cricket song (Sakaluk and Eggert 2009, Morris and Gwynne 1978), the temperature at the time of each audio recording was also measured. Following recording, males were preserved in $70 \%$ ethanol to allow morphological measurements to be taken at a later date.

Raven Pro was used to measure acoustical characteristics for each male including pulse duration (PD), interpulse duration (IPD), train duration (TD), intertrain duration (ITD), and dominant frequency (DF) as illustrated in Figure 1. Prior to analysis, each of these song parameters were adjusted using linear regressions to account for differences in calling due to temperature. After the acoustical features had been measured, their selection surfaces were analyzed using a dichotomous fitness measure (virgin $=0$, nonvirgin $=1$ ).

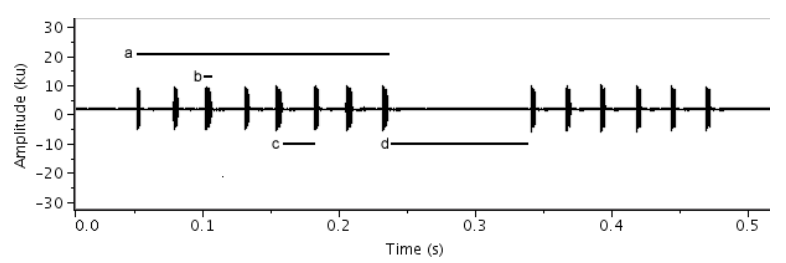

Figure 1. Acoustical characteristics of $C$. strepitans song: a) train duration, b) pulse duration, c) interpulse duration, d) intertrain duration, and f) dominant frequency (not shown). Ower et al.

A multivariate selection analysis was conducted using PopTools (Hood 2009) to estimate the linear and nonlinear sexual selection operating on males' acoustic parameters (Lande and Arnold 1983). Canonical rotation of the nonlinear selection gradients was performed to identify the major axes of sexual selection on the fitness surface (Lande and Arnold 1983). Fitness surfaces were visualized using thin-plate splines (Phillips and Arnold 1989, Green and Silverman 1993), which were estimated using the Tps function from the R Fields statistical package (Furrer et al. 2009). 
Morphological measurements are in progress. Residual body mass from males prior to their preservation will be used as an index of body condition (Jakob 1996, Schulte-Hostedde 2005). Additionally, several morphological features will be measured on each preserved male. Tibial length and pronotum width will be taken as measures of male size. From the left forewing, the harp area and density of teeth on the file will be measured, because both of these characteristics play a key role in song production.

\section{$\uparrow \quad$ RESUltS}

The songs of 167 males from the Dead Man's Bar population were recorded and acoustically analyzed. Of these, 70 males were virgin and 97 males were non-virgin. Prior to conducting the canonical analysis, no significant linear or nonlinear selection was apparent (Table 1). However, canonical rotation of the $\gamma$ matrix revealed significant linear $\left(\mathbf{m}_{1}\right)$ and nonlinear selection $\left(\mathbf{m}_{1}, \mathbf{m}_{2}, \mathbf{m}_{5}\right.$; Table 2$)$. There was significant concave selection along the $\mathbf{m}_{1}$ and $\mathbf{m}_{\mathbf{2}}$ axes and significant convex selection along the $\mathbf{m}_{\mathbf{5}}$ axis (Table 2). The $\mathbf{m}_{\mathbf{1}}$ axis was most strongly influenced by pulse duration and interpulse duration, while the $\mathbf{m}_{2}$ axis was heavily affected by train duration and intertrain duration. The axis of convex selection, $\mathbf{m}_{5}$, was strongly affected by dominant frequency and intertrain duration. Each of the five measured song characteristics played an important role in at least one major axis.

Table 1. The standardized linear selection gradients $(\beta)$ and the matrix of standardized quadratic and correlational selection gradients $(\gamma)$. Note: $P D=$ pulse duration; IPD $=$ interpulse duration; $\mathrm{DF}=$ dominant frequency; $\mathrm{TD}=$ train duration; ITD $=$ intertrain duration .

\begin{tabular}{lcccccc}
\hline & & \multicolumn{5}{c}{$\gamma$} \\
\cline { 3 - 7 } Property & $\beta$ & PD & IPD & MF & TD & ITD \\
\hline PD & 0.121 & 0.224 & & & & \\
IPD & -0.120 & - & 0.032 & & & \\
MF & 0.003 & 0.026 & -0.030 & -0.184 & & \\
& & & & & & \\
TD & 0.001 & - & 0.182 & 0.025 & 0.114 & \\
ITD & -0.037 & 0.158 & -0.002 & 0.075 & 0.138 & -0.072
\end{tabular}

The $\mathbf{m}_{\mathbf{1}}$ axis was significantly affected by both linear and nonlinear selection (Table 2, Figure 2). Large values of $\mathbf{m}_{\mathbf{1}}$ were strongly favored by selection, which involved having longer pulse durations and shorter interpulse durations. The concave-up peak in attractiveness at high values of $\mathbf{m}_{1}$ in Figures 2 a-b illustrates that males with short pulse durations and long interpulse durations had increased mating success. Evidence of disruptive selection along the $\mathbf{m}_{2}$ axis was found, which primarily favored males that had short or long train durations.

Stabilizing selection favored intermediate values of $\mathbf{m}_{\mathbf{5}}$, which included males that called with a dominant frequency of around $13.2 \mathrm{kHz}$ and average intertrain durations. This resulted in a saddle-shaped fitness surface in the thin-plate splines between $\mathbf{m}_{\mathbf{1}} \&$ $\mathbf{m}_{5}$ and $\mathbf{m}_{2} \& \mathbf{m}_{5}$ (Figures 2 b-c).

\section{$\uparrow \quad$ DISCUSSION}

Our analysis revealed significant linear and nonlinear sexual selection acting on song characteristics of male sagebrush crickets. Each of the five measured song characteristics played an important role in shaping male attractiveness.

Concave-up directional selection strongly favored males with long pulse durations and short interpulse directions. Higher energetic costs could be associated with these two song characteristics beacuse increasing the pulse duration would require maintaining frictional contact between the plectrum and file for a longer period of time, and decreasing interpulse duration would require faster wing movement between pulses. Increased pulse duration has been shown to be energetically costly in other song producing Orthoptera (Hoback and Wagner 1997).

The stabilizing selection found on dominant frequency and intertrain duration is likely due to constraints imposed by female hearing abilities. Males that call outside the optimal hearing range of females or that do not call very often (or have high intertrain durations) are likely to escape detection by females. Stabilizing selection opposing shorter intertrain durations (larger $\mathbf{m}_{5}$ values, Figure 2c) contradicted our expectation that males that called more frequently would be more attractive, but could be an artifact of newly eclosed males that hadn't yet had an opportunity to mate. Our inability to control for time of male eclosion was a limitation of this study. 


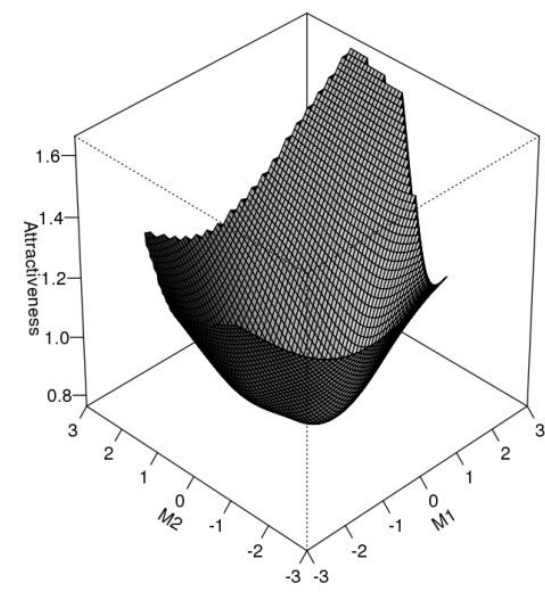

a.

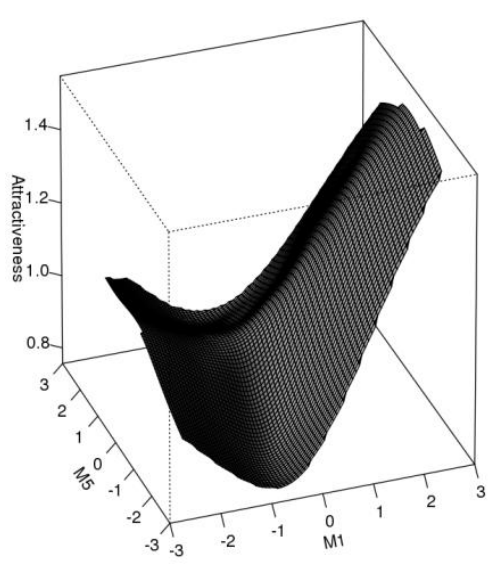

b.

c.

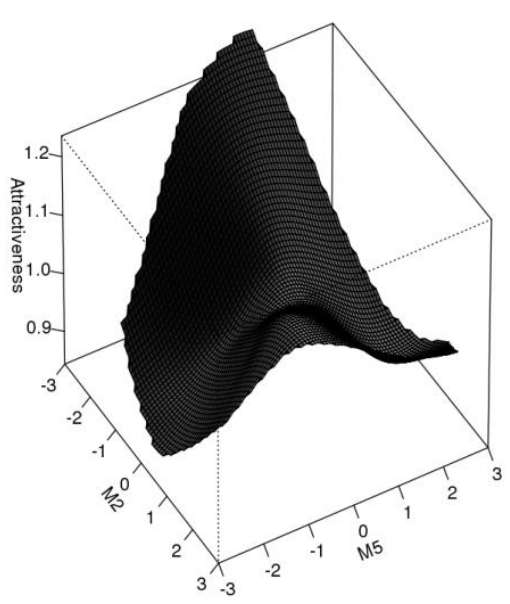

Figure 2. Thin-plate spline visualizations of the fitness surfaces between $(a) \mathrm{m}_{1}$ and $\mathrm{m}_{2},(b) \mathrm{m}_{1}$ and $\mathrm{m}_{5}$, and $(c) \mathrm{m}_{2}$ and $\mathrm{m}_{5}$. Ower et al

Table 2. The M matrix of eigenvectors from the canonical rotation of $\gamma$. Note: ** $P<0.001, * P<0.05$.

\begin{tabular}{ccccccccc}
\hline & \multicolumn{9}{c}{ M } & & & \multicolumn{2}{c}{ Selection } \\
\cline { 8 - 9 } & PD & IPD & MF & TD & ITD & & $\theta_{i}$ & $\lambda_{i}$ \\
\hline $\mathbf{m}_{\mathbf{1}}$ & 0.800 & -0.485 & 0.086 & -0.253 & 0.230 & & $0.147^{*}$ & $0.179^{* *}$ \\
$\mathbf{m}_{\mathbf{2}}$ & 0.312 & 0.357 & 0.107 & 0.749 & 0.450 & & -0.021 & $0.142^{* *}$ \\
$\mathbf{m}_{\mathbf{3}}$ & -0.471 & -0.597 & 0.488 & 0.177 & 0.391 & & 0.002 & -0.051 \\
$\mathbf{m}_{\mathbf{4}}$ & -0.028 & 0.527 & 0.488 & -0.558 & 0.415 & & -0.081 & -0.091 \\
$\mathbf{m}_{5}$ & & & & & & & 0.045 & $-0.121^{*}$ \\
& & & & & & & & \\
\hline
\end{tabular}

Further work will be necessary to confirm that the identified suites of song characteristics are indeed attractive to females. A field study was recently conducted in May and June 2010, in which artificially created sagebrush cricket songs were created and played back to females in binary choice trials conducted in outdoor arenas. The results of this experiment currently are being analyzed.

\section{$\uparrow \quad$ Literature Cited}

Furrer R, Nychka D, Sain S. 2009. Fields: Tools for spatial data. Version 6.3. http://cran.rproject.org/web/packages/fields/index.html

Green PJ, Silverman BW. 1993. Nonparametric regression and generalized linear models: a roughness penalty approach. Boca Raton, Florida: CRC Press.
Hoback WW, Wagner WE. 1997. The energetic cost of calling in the variable field cricket, Gryllus lineaticeps. Physiological Entomology 22:286-290.

Hood GM. 2009. PopTools version 3.1.1. http://www.cse.csiro.au/poptools

Jakob EM, Marshall SD, Uetz GW. 1996. Estimating fitness: a comparison of body condition indices. Oikos 77:61-67.

Lande R, Arnold SJ. 1983. The measurement of selection on correlated characters.Evolution 37(6):1210-1226.

Leman JC, Weddle CB, Gershman SN, Kerr AM, Ower GD, St. John JM. Vogel LA, Sakaluk SK. 2009. Lovesick: immunological costs of mating to male sagebrush crickets. Journal of Evolutionary Biology 22:163-171. 
Morris GK, Gwynne DT. 1978. Geographic distribution and biological observations of Cyphoderris (Orthoptera: Haglidae) with a description of a new species. Psyche 85: 147-167.

Morris GK, Gwynne DT, Klimas DE, Sakaluk SK. 1989. Virgin-male mating advantage in a primitive acoustic insect (Orthoptera: Haglidae). Journal of Insect Behavior 2: 173-185.

Phillips PC, Arnold SJ. 1989. Visualizing multivariate selection. Evolution 43:12091222.
Sakaluk SK, Eggert AK. 2009. Coping with the cold: temperature and mating activity of male sagebrush crickets Cyphoderris strepitans (Orthoptera: Haglidae), Physiological Entomology 34:251-255.

Sakaluk SK, Ivy TM. 1999. Virgin-male mating advantage in sagebrush crickets: differential male competitiveness or non-independent female mate choice? Behaviour 136:13351346.

Schulte-Hostedde AI, Zinner B, Millar JS, Hickling GJ. 2005. Restitution of mass-size residuals: validating body condition indices. Ecology $86: 155-163$. 